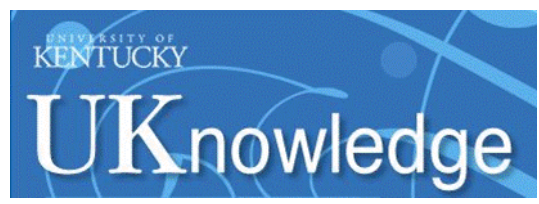

University of Kentucky

UKnowledge

\title{
POSTTRAUMATIC STRESS AND RISKY SEX IN TRAUMA-EXPOSED COLLEGE STUDENTS: THE ROLE OF PERSONALITY DISPOSITIONS TOWARD IMPULSIVE BEHAVIOR
}

Jessica Flores

University of Kentucky, jfl239@g.uky.edu

Digital Object Identifier: https://doi.org/10.13023/etd.2019.200

Right click to open a feedback form in a new tab to let us know how this document benefits you.

\section{Recommended Citation}

Flores, Jessica, "POSTTRAUMATIC STRESS AND RISKY SEX IN TRAUMA-EXPOSED COLLEGE STUDENTS:

THE ROLE OF PERSONALITY DISPOSITIONS TOWARD IMPULSIVE BEHAVIOR" (2019). Theses and Dissertations--Psychology. 160.

https://uknowledge.uky.edu/psychology_etds/160

This Master's Thesis is brought to you for free and open access by the Psychology at UKnowledge. It has been accepted for inclusion in Theses and Dissertations--Psychology by an authorized administrator of UKnowledge. For more information, please contact UKnowledge@lsv.uky.edu. 


\section{STUDENT AGREEMENT:}

I represent that my thesis or dissertation and abstract are my original work. Proper attribution has been given to all outside sources. I understand that I am solely responsible for obtaining any needed copyright permissions. I have obtained needed written permission statement(s) from the owner(s) of each third-party copyrighted matter to be included in my work, allowing electronic distribution (if such use is not permitted by the fair use doctrine) which will be submitted to UKnowledge as Additional File.

I hereby grant to The University of Kentucky and its agents the irrevocable, non-exclusive, and royalty-free license to archive and make accessible my work in whole or in part in all forms of media, now or hereafter known. I agree that the document mentioned above may be made available immediately for worldwide access unless an embargo applies.

I retain all other ownership rights to the copyright of my work. I also retain the right to use in future works (such as articles or books) all or part of my work. I understand that I am free to register the copyright to my work.

\section{REVIEW, APPROVAL AND ACCEPTANCE}

The document mentioned above has been reviewed and accepted by the student's advisor, on behalf of the advisory committee, and by the Director of Graduate Studies (DGS), on behalf of the program; we verify that this is the final, approved version of the student's thesis including all changes required by the advisory committee. The undersigned agree to abide by the statements above.

Jessica Flores, Student

Dr. Christal L. Badour Hirsch, Major Professor

Dr. Mark T. Filmore, Director of Graduate Studies 
POSTTRAUMATIC STRESS AND RISKY SEX IN TRAUMAEXPOSED COLLEGE STUDENTS: THE ROLE OF PERSONALITY DISPOSITIONS TOWARD IMPULSIVE BEHAVIOR

\author{
THESIS \\ A thesis submitted in partial fulfillment of the \\ requirements for the degree of Master of Science in the \\ College of Arts and Sciences \\ at the University of Kentucky \\ By \\ Jessica Flores \\ Lexington, Kentucky \\ Director: Dr. Christal L. Badour Hirsch, Professor of Psychology \\ Lexington, Kentucky \\ 2019
}

Copyright (C) Jessica Flores 2019 


\begin{abstract}
OF THESIS
POSTTRAUMATIC STRESS AND RISKY SEX IN TRAUMAEXPOSED COLLEGE STUDENTS: THE ROLE OF PERSONALITY DISPOSITIONS TOWARD IMPULSIVE BEHAVIOR
\end{abstract}

Posttraumatic stress disorder (PTSD) has been linked to heightened engagement in risky sexual behavior (RSB) across diverse samples, and impulsivity has been postulated as a potential linkage (Weiss et al., 2012). Limited information has been published on the role that impulsivity can play in strengthening the relationship between PTSD and RSB in college students. The current study examined the moderating role of impulsivity dispositions: negative/positive urgency, (lack of) perseverance, sensation seeking, and (lack of) premeditation on the association between PTSD symptoms and past-year RSB among a sample of 221 undergraduate students (77.4\% female) with at least one DSM-5 defined traumatic event. Negative binomial regression models were conducted to explore each impulsivity disposition's moderating effect on the relationship between PTSD symptoms and RSB. PTSD symptoms and positive urgency, (lack of) perseverance, and sensation seeking were independently associated with RSB. Significant interactions were found between negative urgency and PTSD symptoms, and (lack of) premeditation and PTSD

symptoms, such that PTSD symptoms were more strongly linked to RSB among individuals high in these impulsivity dispositions. The present study expands on the limited literature on the role specific impulsivity dispositions can have in the relationship between PTSD and RSB in traumaexposed college students.

KEYWORDS: Posttraumatic Stress Disorder, Trauma-Exposed, Impulsivity, Risky Sexual Behavior, College Students.

Jessica Flores

04/26/2019

Date 
POSTTRAUMATIC STRESS AND RISKY SEX IN TRAUMAEXPOSED COLLEGE STUDENTS: THE ROLE OF PERSONALITY DISPOSITIONS TOWARD IMPULSIVE BEHAVIOR

\author{
By \\ Jessica Flores
}

Christal L. Badour Hirsch, Ph.D.

Director of Thesis

Mark T. Filmore, Ph.D.

Director of Graduate Studies

$04 / 26 / 2019$

Date 


\section{DEDICATION}

This thesis is dedicated to my parents, María Irene and Juan Flores-Sánchez, and my siblings, Michelle, Steven, and Giovanni. Thank you for the continued love and support you all have provided me through this journey. Los quiero por siempre. 


\section{ACKNOWLEDGMENTS}

I would like to first express my gratitude to my thesis chair, Dr. Christal L. Badour Hirsch, for her incredible support and feedback throughout my completion of this project. Additionally, I would like to thank the other members of my thesis committee, Drs. Jessica Burris and Gregory Smith, for the invaluable feedback they provided during my proposal and defense presentations. I would also like to thank the many mentors I have had throughout my academic career, particularly those at DePaul University and Case Western Reserve University.

I would like to thank my graduate student colleagues: my fellow STARRC lab members, C. Alex Brake, Alyssa Jones, and Caitlyn Hood, as well as members in the program, Kullen Balthrop, Pevitr Bansal, Patrick Goh, and Jessica Rivera Rivera, for the assistance, moral support, and feedback they provided in helping me complete this milestone. Lastly, I would like to express my sincerest gratitude to my friends outside of my graduate program, all of whom have provided me with endless love and encouragement through my academic pursuits. 


\section{TABLE OF CONTENTS}

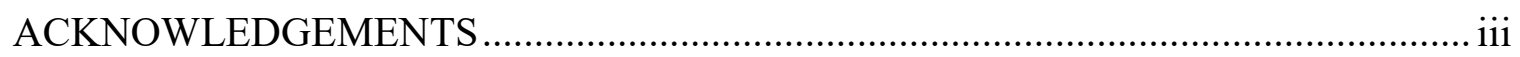

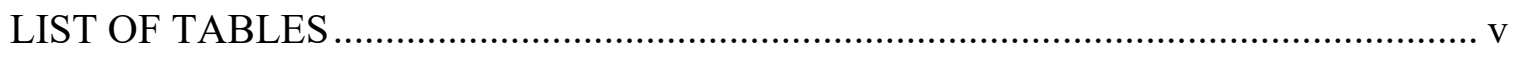

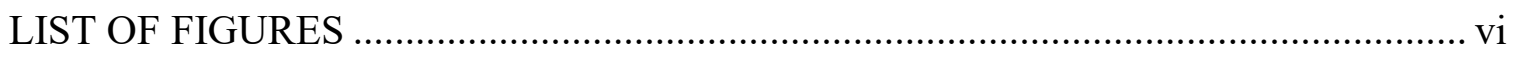

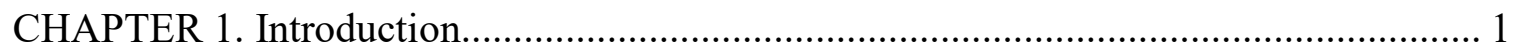

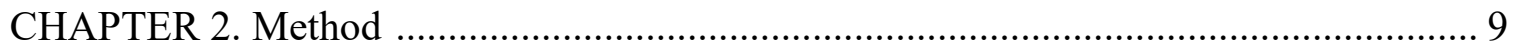

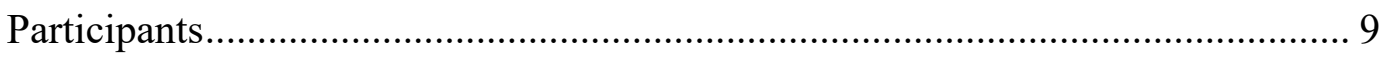

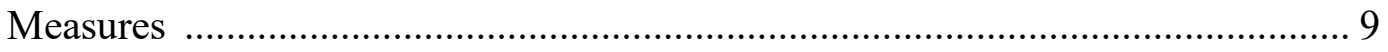

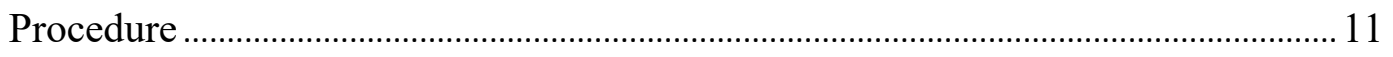

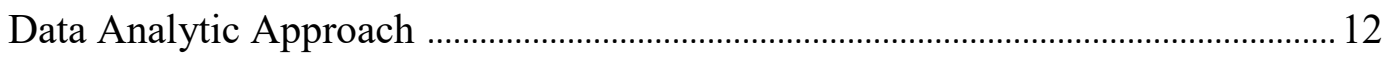

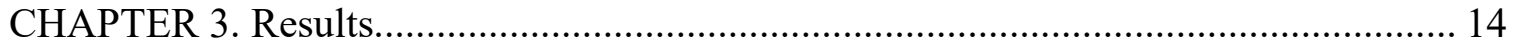

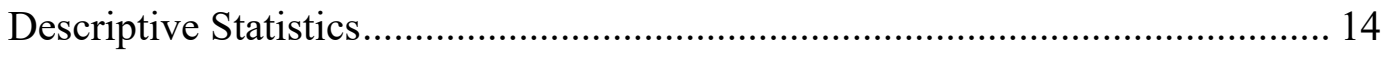

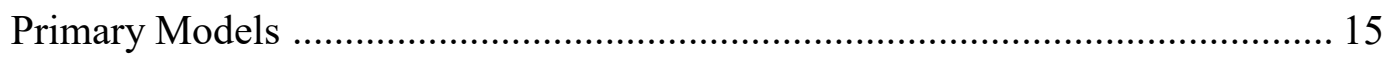

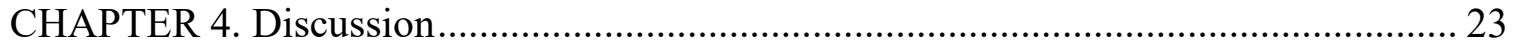

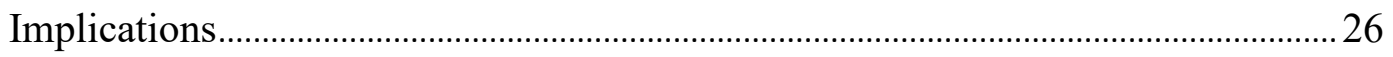

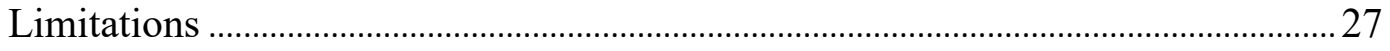

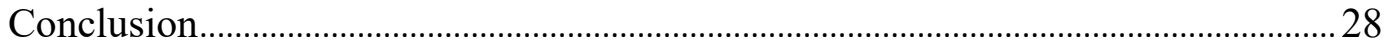

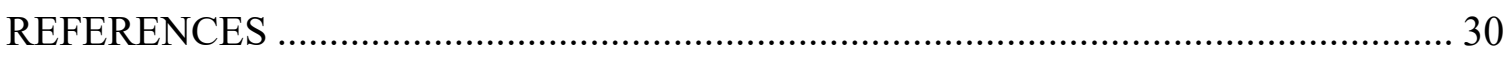

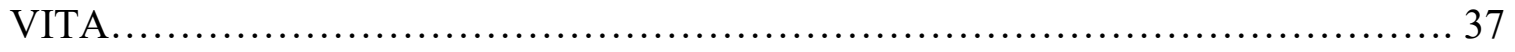




\section{LIST OF TABLES}

Table 1 Number of Risky Sexual Acts, Individual Impulsivity Facets, and PTSD Symptom Severity Means by Biological Sex .............................................................. 17

Table 2 Individual Impulsivity Facets and PTSD Symptom Severity Means by Report of Any Sexual Trauma 18

Table 3 Interactions between PTSD Symptom Severity and Impulsivity Predicting Number of Risky Sexual Acts.................................................................................. 19 


\section{LIST OF FIGURES}

Figure 1 Interaction Between Negative Urgency and Posttraumatic Stress Disorder (PTSD) Symptom Severity on Risky Sexual Behavior 21

Figure 2 Interaction Between (Lack of) Premeditation and Posttraumatic Stress Disorder (PTSD) Symptom Severity on Risky Sexual Behavior .......................................... 22 


\section{CHAPTER 1. INTRODUCTION}

The fifth edition of the Diagnostic and Statistical Manual of Mental Disorders (DSM-5), introduced several changes to the diagnosis of posttraumatic stress disorder (PTSD), including the addition of a new symptom: reckless and self-destructive behaviors (criterion E2; American Psychiatric Association, 2013). It has long been recognized that individuals with PTSD frequently engage in risky behavior; defined as any action that renders a person susceptible to negative emotional, financial, physical or social consequences (Byrnes, Miller, \& Schaffer, 1999). However, the addition of the E2 symptom was made in response to evidence that engagement in potentially harmful and risky behaviors (e.g., risky sex, substance use) is a prevalent and characteristic feature of the PTSD diagnosis (Contractor et al., 2017).

Risky sexual behavior (e.g., unprotected sex, sex under the influence of drugs or alcohol, sex with multiple partners, sex in exchange for money or substances) has been noted as one frequent risk behavior linked to PTSD symptoms across diverse populations, including among substance users (Banducci, Hoffmann, Lejuez, \& Koenen, 2014), those with PTSD resulting from childhood sexual abuse or other interpersonal traumas (Cavanaugh, Hansen, \& Sullivan, 2010; Holmes, Foa, \& Sammel, 2005; MessmanMoore, Walsh, \& DiLillo, 2010; Walsh, Latzman, \& Latzman, 2014), men who have sex with men (Reisner, Mimiaga, Safren, \& Mayer, 2009), and incarcerated women (Hutton et al., 2001). One population in need of further study with regard to PTSD symptoms and risky sexual behavior is college students.

There are unique developmental and environmental characteristics specific to college students that make their engagement in risky sexual behavior different from other 
samples. During this critical developmental period, college students experience increased independence and exposure to new environments, which can facilitate their engagement in risky behaviors (Brooks-Gunn \& Paikoff, 1997; Fromme, Corbin, \& Kruse, 2008; Stinson, 2010). Many college students report engaging in recent sexual activity (Blayney et al., 2018; Dennison, Wu, \& Ickes, 2014). Moreover, "hooking up" has become a widespread term used to reference a range of physically intimate activities, from kissing to sexual intercourse, that tend to occur within non-committed relationships (Paul \& Hayes, 2002; Owen et al., 2010). Further, the influence of the "hook up" culture during this period may increase exploration in sexual activity in college students, making certain sexual behaviors, such as casual sexual activity, sex under the influence of substances, and sexual acts with noncommitted sexual partners, more common (Blayney et al., 2018; Epstein, Calzo, Smiler, \& Ward, 2009; Garcia et al., 2012). Risky sexual behavior can put college students at risk for potentially negative health outcomes, such as unplanned pregnancies and exposure to sexually transmitted diseases (STDs). The prevalence of STDs continues to rise across various demographic groups in the US, and fifteen to twenty-four-year-olds account for approximately $50 \%$ of the 20 million new STD cases reported annually (Center for Disease Control [CDC], 2017).

Risky sexual behavior is common in college students (Cooper, 2002). On average, college students report having two or more sexual partners in the previous 12 months (American College Health Association, 2012; Oswalt \& Wyatt, 2014). Across studies, college students also report similar rates of unprotected sexual activity; between $42.0 \%$ $56.0 \%$ indicated not using a condom during recent vaginal sex, $68.6 \%-79.8 \%$ for anal sex, and 94.3\% - 95.7\% for recent oral sex (American College Health Association, 2012; 
Buhi et al., 2010; Eisenberg, Lust, \& Garcia, 2014; Oswalt \& Wyatt, 2014). Although few studies have examined how PTSD symptoms are linked to risky sexual behavior specifically in college students, those that have demonstrate positive associations. One study found that trauma-related intrusions associated with experiences of child physical or sexual abuse were linked to more frequent casual sex for both male and female students, and to impulsive sexual behavior in females (Walsh, Latzman, \& Latzman, 2014). Two additional studies found that PTSD symptoms were associated with greater engagement in a range of maladaptive coping responses in female students, including using sex to cope with experiences of childhood sexual, physical, and emotional abuse (Filipas \& Ullman, 2006; Messman-Moore, Ward, Brown, 2009). Finally, in a small sample of African American female college students, Munroe and colleagues (2010) found that PTSD symptoms were linked to a higher number of lifetime sexual partners, lower sexual control, and more frequent unprotected vaginal sex and sex under the influence of substances. In sum, preliminary evidence links PTSD symptoms with risky sexual behavior in college students, but additional research is needed to understand the nature of this relationship in both female and male students.

Several possible explanations for the relationship between PTSD and risky behaviors (including risky sex) have been postulated. Individuals with PTSD may engage in risky behaviors in an attempt to reduce or avoid intense negative emotional reactions (i.e., tension-reduction; Baker et al., 2004; Batten Folette, \& Aban, 2002; Filipas \& Ullman, 2006; Messman-Moore, Walsh \& DiLillo, 2010). Conversely, risky behaviors can also be used as a way to generate, prolong or intensify positive affect (Cox \& Klinger, 1988; Nock \& Prinstein, 2004). Personality characteristics, such as impulsivity (i.e., the 
tendency to act on impulse), have also been linked to increased engagement in risk-taking behaviors, and several studies have focused on the association between impulsivity and risky sexual behaviors specifically (Weiss et al., 2015; Weiss et al., 2012). Although multiple definitions of impulsivity exist (Birkley \& Smith, 2011), Whiteside and Lynam (2001; and later Cyders and Smith, 2007, 2008) outlined a model of impulsive personality traits derived from factor analytic studies of existing personality measures of impulsivity. This model identifies four personality traits that are related to impulsive behavior: 1) sensation seeking - the tendency to seek and relish activities that invoke thrill, 2) urgency — the tendency to experience strong impulses to act rashly in the presence of strong affect, 3) (lack of) premeditation - the tendency to engage in an action before contemplating the consequences of said action, and 4) (lack of) perseverance- the tendency to experience difficulty with being diligent in completing tasks. The initial model only focused on urgency solely in the context of negative affect, but Cyders and Smith $(2007,2008)$ later expanded this to include positive urgency as well.

Most of the research on impulsivity and risky sexual behavior in college students has focused on the roles of sensation seeking (Deckman \& DeWall, 2011; Hoyle, Fejfar, \& Miller, 2000; Miller et al., 2003; Zapolski et al., 2009) and negative/positive urgency (Birthrong \& Latzman, 2014; Deckman and Dewall, 2011). One study found that sensation seeking prospectively predicted lifetime engagement in risky sexual behavior in male and female college students, even after controlling for alcohol and drug use and other impulsivity facets (Deckman \& DeWall, 2011). Another cross-sectional study found a significant positive zero-order relation between sensation seeking and risky sexual behavior, but sensation seeking did not uniquely predict overall risky sex or 
specific types of risky sexual acts (e.g., risky anal sex, intent to engage in risky sex, impulsive sexual behavior, risky sex with uncommitted partners) when the other four impulsivity dispositions were simultaneously entered in the same model (Birthrong \& Latzman, 2014). Entering all five impulsivity facets together is a conservative data analytic method and highlights that other impulsivity dispositions may be more relevant and uniquely linked to risky sexual behavior.

As applied to PTSD, there is some evidence that sensation seeking may actually serve as a protective factor following a traumatic event. Individuals who are high in sensation seeking appear to have a greater threshold for experiencing distress in response to intense and potentially traumatic stimuli and are more likely to use problem-focused active coping strategies to deal with traumatic experiences (Solomon, Gizburg, Neria, \& Ohry 1995). Despite serving as a potential protective factor against developing PTSD, sensation seeking may still serve to strengthen the relationship between PTSD symptomatology and risky sexual behavior, as individuals high in sensation seeking tend to be drawn to activities that bring forth excitement and thrill that may serve as distraction from distress (i.e., tension-reduction strategy) or may counter the dampening of positive affect associated with PTSD (i.e., prolonging positive affect; Horvath \& Zuckerman, 1993; Zuckerman, 1994).

Several studies have also demonstrated that both negative and positive urgency are linked to more frequent risky sexual behavior in college students (Birthrong \& Latzman, 2014; Deckman and Dewall, 2011; Simons, Maisto, \& Wray, 2010; Zapolski et al., 2009). However, at least one study suggests the role of positive urgency may differ for males and females (Simons et al., 2010). Individuals with PTSD may be more likely to 
engage in risky sexual behavior in response to strong negative emotions associated with PTSD if they also tend to engage in rash action in the context of strong negative emotion (i.e., negative urgency). Having strong positive urgency in the context of PTSD may be linked to higher engagement in risky sex behavior, because these behaviors may either evoke or extend positive emotional states in a group of people who are experiencing significant reductions in positive emotions.

The remaining dispositions of impulsivity, (lack of) premeditation and (lack of) perseverance, have received considerably less focus in understanding risky sexual behavior. However, both (lack of) premeditation and (lack of) perseverance are thought to reflect low trait conscientiousness, a characteristic that may lead individuals to view the benefits of engaging in risky sexual behavior to outweigh the possible ramifications (Bogg \& Roberts, 2004). Although several studies have documented positive correlations between (lack of) premeditation and risky sexual behavior (Birthrong \& Latzman, 2014; Deckman \& DeWall, 2011; Miller et al., 2003; Simons et al., 2010), findings for (lack of) perseverance have been mixed. One study found that (lack of) perseverance was actually associated with both later initiation of sexual behavior and fewer sexual partners in college students (Miller et al., 2003). In contrast, Birthrong and Latzman (2014) found that (lack of) perseverance was positively related to overall risky sexual behavior as well as the specific types of risky sexual behavior assessed in the study, but (lack of) perseverance did not significantly predict engagement in risky sex when controlling for the effect of the other impulsivity dispositions. Another study found the association of (lack of) perseverance and risky sexual behavior was rendered non-significant when accounting for the effects of alcohol and drug use (Deckman \& Dewall, 2011). 
Though, less is known regarding how (lack of) premeditation and (lack of) perseverance may relate to risky sexual behavior, there are potential characteristics of these impulsivity dispositions that may modify the relationship between PTSD symptoms and risky sexual behavior. (Lack of) premeditation and/or perseverance may lead individuals to experience increased difficulty considering and favoring the long-term negative consequences of engaging in risky sex, when such behavior can serve to immediately reduce their PTSD-related distress or enhance their positive emotional experience that has been diminished as a result of PTSD. As such, these traits may result in a strengthened relationship between PTSD symptoms and risky sex in a way that maps onto both the tension-reduction and the prolonging positive affect models.

In sum, both impulsivity and PTSD have individually been linked with increased engagement in risky sexual behavior. However, to our knowledge, relatively few studies have looked at the influence of impulsivity dispositions in the association between PTSD and risky sexual behaviors in college students. The purpose of the current study was to further elucidate the role of impulsivity dimensions in the association between PTSD and risky sexual behavior in college students by examining the moderating role of individual impulsivity dispositions (i.e., sensation seeking, negative urgency, positive urgency, [lack of] premeditation, and [lack of] perseverance) in the association between PTSD symptoms and past-year risky sexual behavior in a sample of trauma-exposed college students $(N=221 ; 77.4 \%$ female $)$ at a large, public university in Southeastern U.S. It was hypothesized that the positive association between PTSD and risky sexual behavior, would be stronger among participants high in specific impulsive personality traits. Specifically, it was expected that the traits of sensation seeking and negative/positive 
urgency would have the strongest moderating effects in the association between PTSD symptoms and risky sexual behavior. 


\section{CHAPTER 2. METHOD}

\section{Participants}

The present study utilized a sample of 221 college-aged adults $\left(M_{\text {age }}=18.67, S D\right.$ $=0.95 ; 77.4 \%$ female) who reported a history of at least one DSM-5 defined Criterion A traumatic event (American Psychiatric Association, 2013). The sample was predominantly Caucasian $(n=190 ; 86.0 \%)$, non-Hispanic $(n=210 ; 94.9 \%)$, single $(n=$ $216 ; 97.7 \%)$, and heterosexual $(n=209 ; 94.6 \%)$ with some college experience $(n=216$; 97.8\%). Additional racial groups identified in the sample included: African American ( $n$ $=16 ; 7.2 \%)$, Asian $(n=3 ; 1.4 \%)$, American Indian or Alaska Native $(n=1 ; 0.5 \%)$, Multi-Racial $(n=7 ; 3.2 \%)$, and Other $(n=4 ; 1.8 \%)$.

\section{Measures}

Trauma exposure. Participants were asked about exposure to sixteen potentially traumatic events (e.g., natural disasters, serious accidents and injuries, physical or sexual assault, combat exposure, etc.), in accordance with the DSM-5 Criterion A trauma guidelines (American Psychiatric Association, 2013), and this was assessed using the Life Events Checklist (LEC-5; Weathers, Blake et al., 2013b). Participants responded to each item indicating whether or not they had experienced at any point in their life the traumatic event listed directly, indirectly (witnessed or learned about), as part of their occupation, or if they were unsure sure the event fit into their experience. They were then asked to select their index traumatic event (the event they considered the worst) and were asked seven follow-up questions to determine whether this event met for Criterion A eligibility. The participants were asked to report when the index traumatic event happened, their exposure to the event (i.e., directly, indirectly, as part of their occupation 
or other), whether the event involved life threat, serious injury and/or death, sexual violence, and the number of times they experienced this type of traumatic event. If the event involved the death of a close loved one or a friend, participants were asked to report if the death was due to an accident/violence or due to natural causes. Although the psychometric properties of the LEC-5 are still being evaluated, the previous version of the LEC measure exhibited excellent test-retest reliability and good convergent validity with other measures of trauma exposure (Gray et al., 2004).

PTSD symptoms. The PTSD Checklist for DSM-5 (PCL-5; Weathers et al., 2013) was used to assess past-month PTSD symptom severity in response to the index trauma identified by participants on the LEC-5. Participants indicated the degree to which they were bothered by 20 symptoms of posttraumatic stress disorder in the past month using a five-point Likert-type scale $(0=$ not at all to $4=$ extremely $)$. A total score was derived to reflect total PTSD symptom severity with higher scores reflecting greater PTSD symptoms. This measure demonstrates adequate test-retest reliability over one week, as well as convergent and discriminant validity (Blevins, Weathers, Davis, Witte, \& Domino, 2015). In the present sample, internal consistency was excellent $(\alpha=.94)$. A cut score of $\geq 37$ on the PCL-5 demonstrates optimal sensitivity and specificity in predicting probable PTSD among college students (Blevins et al., 2015). As such, this score was used to determine presence of probable PTSD for descriptive purposes.

Impulsivity. The 59-item UPPS-P Impulsivity Scale was used to assess personality characteristics that contribute to impulsive behaviors (UPPS-P; Lynam, Smith, Whiteside, \& Cyders, 2006). The UPPS-P has five subscales, which measure different traits of impulsivity: negative urgency (12 items), positive urgency (14 items), sensation 
seeking (12 items), (lack of) premeditation, and (lack of) perseverance (10 items). Items are scored on a four-point Likert-type scale $(1=$ agree strongly to $4=$ disagree strongly $)$, with higher scores reflecting greater impulsivity. Internal consistency for the scales in the present sample were acceptable to excellent: negative urgency $(\alpha=.89)$, positive urgency ( $\alpha=.95)$, sensation seeking ( $\alpha=.95)$, (lack of) premeditation $(\alpha=.80)$, and (lack of) perseverance $(\alpha=.78)$. The UPPS-P demonstrates good convergent and divergent validity (Smith et al., 2007).

Risky sexual behavior. The frequency of risky sexual acts participants engaged in over the past year was assessed using a subset of items from the Risky Behavior Questionnaire (RBQ; Weiss, Tull, Dixon-Gordon, \& Gratz, 2018). Participants responded to six items indicating the number of times over the past year they participated in a variety of risky sexual acts, including unprotected sex with a non-monogamous partner, a one-night stand, sex in exchange for drugs or money, payment for sex using drugs or money, sex with a non-monogamous partner while under the influence of alcohol or drugs, and sex with a stranger. This is the first study to specifically examine the risky sexual behavior items of the RBQ frequency subscale; however, the overall RBQ measure has demonstrated strong convergent validity with other measures of risky behavior (Weiss et al., 2018).

\section{Procedure}

Participants in this study were enrolled in the study using the SONA System, an online portal aimed at recruiting undergraduate research participants. Participant data was collected via Qualtrics, an online research survey platform, and they received course credit for their participation in the study. Participants first provided electronic consent for 
their participation. They were then screened for exposure to a Criterion A traumatic event. Eligible participants were then asked to complete the measures for this study as well as other questionnaires not relevant to the current investigation. The University of Kentucky's Institutional Review Board approved all study procedures.

\section{Data Analytic Approach}

A series of independent samples $t$-tests were conducted to examine whether scores for the individual impulsivity facets and PTSD symptom severity differed by participant biological sex (i.e., male/female) and endorsement of history of sexual trauma. Degrees of freedom were adjusted when violations of the homogeneity of variance assumption emerged. To test whether the difference in scores for risky sexual behavior varied as a function of biological sex and history of sexual trauma, separate negative binomial regression models predicting frequency of risky sexual behavior were conducted with biological sex and history of sexual trauma included as predictors, respectively. Primary hypotheses predicting the frequency of risky sexual behavior were evaluated using a series of negative binomial regression models. PTSD symptom severity was included as a predictor in all models. Separate models also included each impulsivity facet and the interaction between PTSD and each impulsivity facet as additional predictors. Biological sex $(0=$ male, $1=$ female $)$ and sexual trauma history $(0=$ yes, $1=$ no to aid in interpretation in regression models) were both positively associated with the number of risky sexual acts and were thus included as covariates in the primary models. Continuous variables were mean-centered based on the recommendations for testing interactions in negative binomial regression models. Interactions found to be significant 
were then probed using two-way negative-binomial interactions model plots (Dawson, 2014). 


\section{CHAPTER 3. RESULTS}

\section{Descriptive Statistics}

The average number of past-year risky sexual acts reported by participants was $2.93(S D=8.16)$. Approximately $34.4 \%(n=76)$ of the total sample reported engaging it at least one risky sexual act in the past-year, and the average number of risky sexual acts reported by this subsample was $8.51(S D=12.12)$. The most commonly reported acts included having unprotected sex with a non-monogamous partner (23.1\%) and having a one-night stand (23.1\%). Participants also reported having sex with a non-monogamous partner while under the influence of alcohol or drugs $(22.6 \%)$, having sex with someone they did not know very well $(21.7 \%)$, having sex in exchange for drugs or money $(1.4 \%)$, and paying for sex using drugs or money $(0.9 \%)$.

Twenty one percent of participants in the sample endorsed a history of sexual trauma, although a smaller number $(8.1 \%)$ identified an unwanted sexual experience as their most distressing or index traumatic event. The remaining participants reported a diverse range of index events including sudden death of a loved one (35.4\%), life threatening illness or injury (17.2\%), serious accident, fire or explosion (15.4\%), natural disaster (6.3\%), physical assault (2.7\%), military combat or time spent in a war zone $(0.9 \%)$, captivity $(0.5 \%)$, or other traumatic experience $(13.6 \%)$. Approximately $9.5 \%$ of the sample $(n=21)$ met criteria for probable PTSD.

A chi-square test of independence was performed to examine the relation between biological sex and sexual trauma, and was not significant, $X^{2}(1, N=221)=2.04, p=.15$. As displayed in Table 1, men in the study reported a higher number of risky sexual acts and higher scores on sensation seeking in comparison to women. In contrast, women 
displayed higher PTSD symptom severity compared to males. Biological sex was positively associated with frequency of risky sexual acts, such that the relationship between risky sexual acts and biological sex was greater among male participants. As displayed in Table 2, individuals with a history of sexual trauma reported a higher number of risky sexual acts, and displayed higher scores for negative urgency, (lack of) premeditation, (lack of) perseverance and PTSD symptom severity than those without a history of sexual trauma. Lastly, history of sexual trauma was positively related to the number of risky sexual acts.

\section{Primary Models}

Results from the five separate negative binomial regression models examining predictors of risky sexual behavior are displayed in Table 3.

In Model 1, PTSD symptom severity and sensation seeking were both significantly positively associated with number of risky sexual acts. However, the interaction between sensation seeking and PTSD symptom severity was not significant. In Model 2, negative urgency was positively associated with risky sexual acts and there was a significant interaction between negative urgency and PTSD symptom severity, such that the relationship between PTSD symptoms and risky sexual acts was stronger among individuals high in negative urgency (see Figure 1). In Model 3, PTSD symptom severity and positive urgency both were significantly positively associated with the number of risky sexual acts. However, the interaction between positive urgency and PTSD symptom severity was not significant. In Model 4, PTSD symptom severity was positively associated with the number of risky sexual acts and there was a significant interaction between (lack of) premeditation and PTSD symptom severity, such that the 
relationship between PTS symptoms and risky sexual acts was stronger among individuals high in (lack of) premeditation (see Figure 2). In the final model, PTSD symptom severity and (lack of) perseverance were both found to be positively associated with the number of risky sexual acts. However, the interaction between (lack of) perseverance and PTSD symptom severity on risky sexual acts was not significant. 
Table 1. Number of Risky Sexual Acts, Individual Impulsivity Dispositions, and PTSD Symptom Severity Means by Biological Sex

\begin{tabular}{|c|c|c|c|c|c|c|c|c|c|c|c|c|}
\hline & \multicolumn{2}{|c|}{ Overall } & \multicolumn{2}{|c|}{ Females } & \multicolumn{2}{|c|}{ Males } & & & & & & \\
\hline & $M$ & $S D$ & $M$ & $S D$ & $M$ & $S D$ & $t$ & $B$ & $S E$ & Wald $\chi^{2}$ & IRR & $95 \% \mathrm{CI}$ \\
\hline Risky Sexual Acts & 2.93 & 8.16 & 2.09 & 5.11 & 5.78 & 14.05 & -- & $1.02 * * *$ & .18 & 32.13 & 2.76 & $1.94-3.92$ \\
\hline Sensation Seeking & 2.85 & 0.60 & 2.79 & 0.61 & 3.09 & 0.53 & $3.24 * *$ & -- & -- & - & -- & -- \\
\hline Negative Urgency & 2.32 & 0.56 & 2.34 & 0.56 & 2.24 & 0.57 & -1.13 & - & -- & -- & -- & -- \\
\hline Positive Urgency & 2.01 & 0.65 & 1.98 & 0.66 & 2.11 & 0.60 & 1.24 & -- & -- & -- & -- & -- \\
\hline (Lack of) Premeditation & 2.03 & 0.42 & 2.02 & 0.43 & 2.08 & 0.38 & 0.94 & -- & -- & - & -- & -- \\
\hline (Lack of) Perseverance & 1.95 & 0.42 & 1.95 & 0.43 & 1.95 & 0.40 & -0.09 & -- & -- & -- & -- & -- \\
\hline $\begin{array}{l}\text { PTSD Symptom } \\
\text { Severity }\end{array}$ & 13.67 & 14.08 & 14.59 & 14.72 & 10.52 & 11.24 & $-2.09 *$ & -- & -- & -- & -- & -- \\
\hline
\end{tabular}

Note. ${ }^{*} p<.05, * * p<.01, * * * p<.001 ; \mathrm{CI}=$ Confidence interval; IRR = Incidence rate ratios; PTSD = Posttraumatic stress disorder; $S D=$ Standard deviation; $S E=$ Standard error 
Table 2. Number of Risky Sexual Acts, Individual Impulsivity Dispositions, and PTSD Symptom Severity Means by Report of Any Sexual Trauma

\begin{tabular}{|c|c|c|c|c|c|c|c|c|c|c|c|c|}
\hline & \multicolumn{2}{|c|}{ Overall } & \multicolumn{4}{|c|}{ Any Sexual Trauma } & & & & & & \\
\hline & \multirow[b]{2}{*}{$M$} & \multirow[b]{2}{*}{$S D$} & \multicolumn{2}{|c|}{ Yes } & \multicolumn{2}{|c|}{ No } & \multirow[b]{2}{*}{$t$} & \multirow[b]{2}{*}{$B$} & \multirow[b]{2}{*}{$S E$} & \multirow[b]{2}{*}{ Wald $\chi^{2}$} & \multirow[b]{2}{*}{ IRR } & \multirow[b]{2}{*}{$95 \% \mathrm{CI}$} \\
\hline & & & $M$ & $S D$ & $M$ & $S D$ & & & & & & \\
\hline Risky Sexual Acts & 2.93 & 8.16 & 4.85 & 11.11 & 2.41 & 7.11 & -- & $.70 * * *$ & .18 & 14.51 & 2.02 & $1.41-2.89$ \\
\hline Sensation Seeking & 2.85 & 0.60 & 2.80 & 0.70 & 2.87 & 0.57 & -0.75 & -- & -- & -- & -- & -- \\
\hline Negative Urgency & 2.32 & 0.56 & 2.52 & 0.55 & 2.27 & 0.56 & $2.75 * *$ & -- & -- & -- & -- & - \\
\hline Positive Urgency & 2.01 & 0.65 & 2.16 & 0.66 & 1.97 & 0.64 & 1.75 & - & -- & - & - & -- \\
\hline (Lack of) Premeditation & 2.03 & 0.42 & 2.17 & 0.49 & 1.99 & 0.39 & $2.28 *$ & - & -- & - & - & -- \\
\hline (Lack of) Perseverance & 1.95 & 0.42 & 2.07 & 0.44 & 1.92 & 0.41 & $2.17^{*}$ & -- & -- & -- & -- & -- \\
\hline PTSD Symptom Severity & 13.67 & 14.08 & 22.96 & 15.12 & 11.16 & 12.71 & $4.90 * * *$ & -- & -- & -- & -- & -- \\
\hline
\end{tabular}

Note. ${ }^{*} p<.05, * * p<.01, * * * p<.001 ; \mathrm{CI}=$ Confidence interval; IRR = Incidence rate ratios; $M=$ Mean; PTSD = Posttraumatic stress disorder; $S D=$ Standard deviation; $S E=$ Standard error. 
Table 3. Interactions between PTSD Symptom Severity and Individual Impulsivity Dispositions Predicting Number of Risky Sexual Acts

\begin{tabular}{|c|c|c|c|c|c|c|c|}
\hline \multirow{2}{*}{ Models } & \multicolumn{2}{|c|}{ Omnibus Test } & \multirow[b]{2}{*}{$B$} & \multirow[b]{2}{*}{$S E$} & \multirow[b]{2}{*}{ Wald $\chi^{2}$} & \multirow[b]{2}{*}{ IRR } & \multirow[b]{2}{*}{$95 \% \mathrm{CI}$} \\
\hline & $\chi^{2}$ & $p$ & & & & & \\
\hline $\begin{array}{l}\text { Model 1. Sensation } \\
\text { Seeking }\end{array}$ & 83.58 & $<.001$ & & & & & \\
\hline Male & & & 1.18 & 0.20 & $36.20 * * *$ & 3.24 & $2.21-4.75$ \\
\hline Sexual Trauma History & & & 0.51 & 0.22 & $5.42 *$ & 1.67 & $1.08-2.57$ \\
\hline Sensation Seeking & & & 0.43 & 0.16 & $6.85^{* *}$ & 1.54 & $1.11-2.12$ \\
\hline PTSD Symptom Severity & & & 0.02 & 0.01 & $11.06^{* *}$ & 1.02 & $1.01-1.04$ \\
\hline $\begin{array}{l}\text { Sensation Seeking } \mathrm{x} \\
\text { PTSD Symptom Severity }\end{array}$ & & & 0.003 & 0.01 & 0.06 & 1.00 & $0.98-1.02$ \\
\hline $\begin{array}{l}\text { Model 2. Negative } \\
\text { Urgency }\end{array}$ & 99.08 & $<.001$ & & & & & \\
\hline Male & & & 1.26 & 0.20 & $41.72 * * *$ & 3.54 & $2.41-5.20$ \\
\hline Sexual Trauma History & & & 0.34 & 0.23 & 2.29 & 1.41 & $0.91-2.18$ \\
\hline Negative Urgency & & & 0.73 & 0.17 & $17.85 * * *$ & 2.07 & $1.48-2.91$ \\
\hline PTSD Symptom Severity & & & 0.01 & 0.01 & 1.23 & 1.01 & $0.99-1.02$ \\
\hline $\begin{array}{l}\text { Negative Urgency } \mathrm{x} \\
\text { PTSD Symptom Severity }\end{array}$ & & & 0.04 & 0.01 & $7.79 * *$ & 1.04 & $1.01-1.06$ \\
\hline Model 3. Positive Urgency & 112.70 & $<.001$ & & & & & \\
\hline Male & & & 1.03 & 0.20 & $27.14 * * *$ & 2.79 & $1.90-4.11$ \\
\hline Sexual Trauma History & & & 0.33 & 0.22 & 2.11 & 1.39 & $0.89-2.15$ \\
\hline Positive Urgency & & & 0.87 & 0.15 & $34.21 * * *$ & 2.38 & $1.78-3.17$ \\
\hline PTSD Symptom Severity & & & 0.02 & 0.01 & $6.90^{* *}$ & 1.02 & $1.01-1.03$ \\
\hline $\begin{array}{l}\text { Positive Urgency } \mathrm{x} \\
\text { PTSD Symptom Severity }\end{array}$ & & & -0.001 & 0.01 & 0.01 & 1.00 & $0.98-1.02$ \\
\hline
\end{tabular}


Table 3. continued.

\begin{tabular}{|c|c|c|c|c|c|c|c|}
\hline \multirow{2}{*}{ Models } & \multicolumn{2}{|c|}{ Omnibus Test } & \multirow[b]{2}{*}{$B$} & \multirow[b]{2}{*}{$S E$} & \multirow[b]{2}{*}{ Wald $\chi^{2}$} & \multirow[b]{2}{*}{ IRR } & \multirow[b]{2}{*}{$95 \% \mathrm{CI}$} \\
\hline & $\chi^{2}$ & $p$ & & & & & \\
\hline $\begin{array}{l}\text { Model 4. (Lack of) } \\
\text { Premeditation }\end{array}$ & 99.60 & $<.001$ & & & & & \\
\hline Male & & & 1.33 & 0.19 & $50.86^{* * *}$ & 3.79 & $2.63-5.46$ \\
\hline Sexual Trauma History & & & 0.22 & 0.23 & 0.90 & 1.24 & $0.80-1.94$ \\
\hline (Lack of) Premeditation & & & 0.34 & 0.22 & 2.26 & 1.40 & $0.90-2.16$ \\
\hline PTSD Symptom Severity & & & 0.02 & 0.01 & $8.30 * *$ & 1.02 & $1.01-1.04$ \\
\hline $\begin{array}{l}\text { (Lack of) Premeditation x } \\
\text { PTSD Symptom Severity }\end{array}$ & & & 0.06 & 0.02 & $16.30 * * *$ & 1.06 & $1.03-1.10$ \\
\hline $\begin{array}{l}\text { Model 5. (Lack of) } \\
\text { Perseverance }\end{array}$ & 81.13 & $<.001$ & & & & & \\
\hline Male & & & 1.24 & 0.19 & $41.96 * * *$ & 3.46 & $2.38-5.03$ \\
\hline Sexual Trauma History & & & 0.47 & 0.22 & $4.60^{*}$ & 1.60 & $1.04-2.47$ \\
\hline (Lack of) Perseverance & & & 0.50 & 0.24 & $4.17^{*}$ & 1.65 & $1.02-2.65$ \\
\hline PTSD Symptom Severity & & & 0.03 & 0.01 & $12.91 * * *$ & 1.03 & $1.01-1.04$ \\
\hline $\begin{array}{l}\text { (Lack of) Perseverance x } \\
\text { PTSD Symptom Severity }\end{array}$ & & & -0.02 & 0.02 & 1.74 & 0.98 & $0.95-1.01$ \\
\hline
\end{tabular}

Note. ${ }^{*} p<.05, * * p<.01, * * * p<.001 ; \mathrm{PTSD}=$ Posttraumatic stress disorder; $S E=$ Standard Error; IRR = Incidence Rate Ratios; CI = Confidence Interval. 
Figure 1. Interaction Between Negative Urgency and Posttraumatic Stress Disorder (PTSD) Symptom Severity on Risky Sexual Behavior

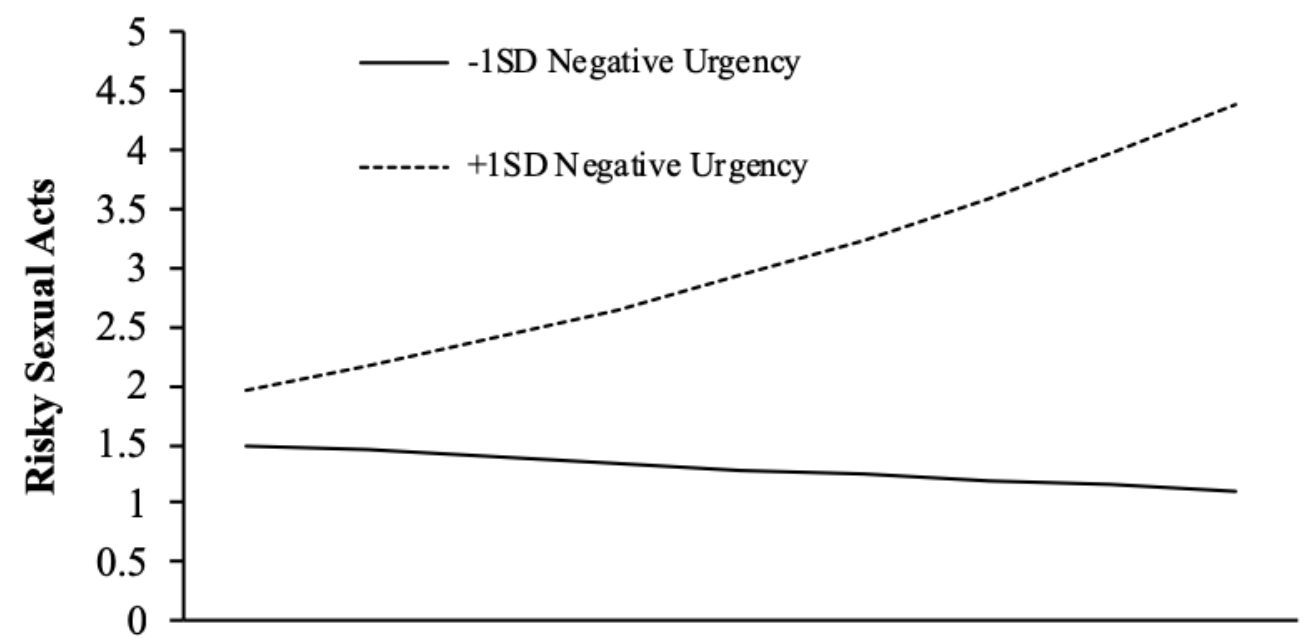

Low PTSD Symptom Severity

High PTSD Symptom Severity 
Figure 2. Interaction Between (Lack of) Premeditation and Posttraumatic Stress Disorder (PTSD) Symptom Severity on Risky Sexual Behavior

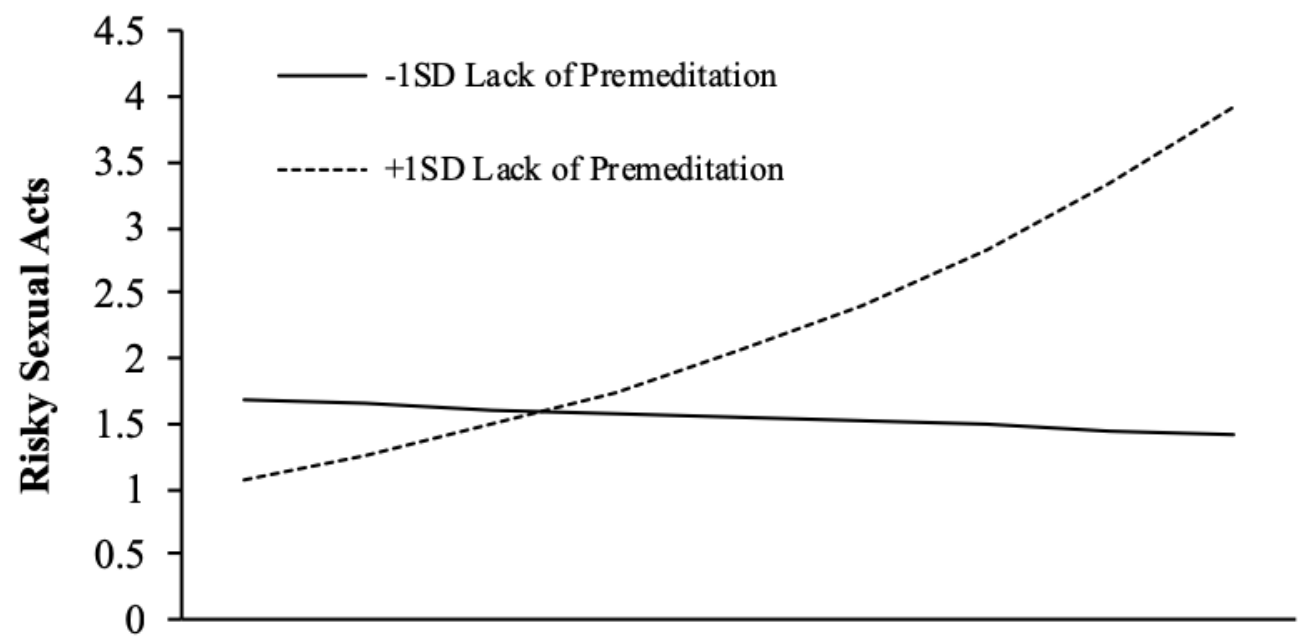

Low PTSD Symptom Severity

High PTSD Symptom Severity 


\section{CHAPTER 4. DISCUSSION}

Symptoms of PTSD have been linked to risky sexual behavior across a range of samples (Banducci, Hoffmann, Lejuez, \& Koenen, 2014; Cavanaugh, Hansen, \& Sullivan, 2010; Hutton et al., 2001; Reisner, Mimiaga, Safren, \& Mayer, 2009), including among college students (Walsh, Latzman, \& Latzman, 2014). There are developmental and environmental factors that make risky sexual behavior in college students different from other populations, including increased freedom associated with the transition to living independently (Brooks-Gunn \& Paikoff, 1997; Fromme, Corbin, \& Kruse, 2008; Stinson, 2010) and the prevalence of the "hook up" culture on college campuses (Owen et al., 2010). Although an association between PTSD and risky sexual behavior has been established, the exact nature of this relationship is still not fully understood. Moreover, existing studies on risky sexual behavior in trauma-exposed college students have primarily been conducted in female samples (Filipas \& Ullman, 2006; Messman-Moore, Ward, Brown, 2009; Munroe et al., 2010), and there is a need to observe this behavior in both females and males.

The present study examined the moderating role of individual personality dispositions toward impulsive behavior (i.e., sensation seeking, negative/positive urgency, [lack of] premeditation, [lack of] perseverance) in the relationship between PTSD symptoms and risky sexual behaviors in a sample of trauma-exposed female and male college students. Consistent with previous studies, male participants in our study were higher in sensation seeking (Cross, Cyrenne, \& Brown, 2013; Shulman, Harden, Chein \& Steinberg, 2015) and reported engaging in more risky sexual acts than female 
participants (Johnson et al., 1994; Newman \& Zimmerman, 2000); while female students reported more severe PTSD symptoms (Christiansen \& Hansen, 2015).

Though it has been noted in prior studies that women are more likely to experience sexual trauma compared to men (Tolin \& Foa, 2008), reports of sexual trauma did not significantly differ by biological sex in the present study, which was unexpected. This lack of finding could potentially be due to the way the sexual trauma variable was calculated in this study, which collapsed across varying forms of unwanted sexual experiences ranging from penetrative rape to other types of unwanted sexual experiences (e.g. touching private parts). By adopting this broader definition of sexual trauma, we were able to capture more diverse experiences of unwanted sexual contact, which is a strength of this study. However, this may have, in turn, not allowed us to see potential differences by biological sex that may have been present in more severe forms of sexual trauma (e.g., penetrative rape). The limited number of men who participated in the present study precluded our ability to conduct sex-specific analyses, which would have been ideal. Due to this sample limitation, biological sex was included as covariate in the analyses in order to account for the influence of biological sex differences in both engagement of risky sex and PTSD symptom severity. Similar to prior studies, having a history of sexual trauma was associated with greater engagement in risky sexual acts (Moore et al., 2017; Smith, Davis, \& Fricker-Elhai, 2004), and was also found to be associated with higher PTSD symptom severity (Olff, 2017; Tolin \& Foa, 2008). Thus, sexual trauma was also included as a covariate in the models to account for its overlap with PTSD symptom severity and risky sexual behaviors. Future studies with greater number of male participants, particularly those with a history of sexual trauma, are 
needed in order to tease apart the unique impact of biological sex and sexual trauma in the context of risky sexual behavior engagement in college students. Interestingly, participants with a history of sexual trauma scored higher on the negative urgency, (lack of) premeditation, and (lack of) perseverance dimension in comparison to those without a history of sexual trauma. Given the cross-sectional nature of this study, it is impossible to disentangle the nature of the relationship between sexual trauma and these specific personality traits. Potentially, individuals who are high on negative urgency, (lack of) premeditation, or (lack of) perseverance may be more at-risk for experiencing sexual trauma than those who are lower on these personality traits. On the other hand, it could be that experiencing a sexual trauma may lead to an increase in these impulsive personality traits. Longitudinal studies are needed to further investigate the directionality of the relationship between sexual trauma and these impulsivity dispositions.

In the present study, the negative urgency and (lack of) premeditation impulsivity dispositions were each found to moderate the relation between PTSD symptom severity and risky sexual behavior. As predicted, as PTSD symptom severity increased, engagement in risky sexual behavior increased more robustly among those who were high in negative urgency and those who were high in (lack of) premeditation. One theory proposes that risky sexual behaviors may serve as an emotion regulation strategy among individuals with PTSD, such that some individuals may engage in risky sexual behaviors as a means to mitigate or avoid strong negative affect, while others may engage in risky sexual behavior to help promote or prolong experiences of positive emotions (notably, the two are not mutually exclusive). Being high in the negative urgency personality disposition may put them more at-risk for impulsively engaging in risky sexual behaviors 
when experiencing high negative affect that accompanies symptoms of PTSD, as this negative urgency is associated with a greater disposition toward rash action in the presence of strong negative emotion.

Among individuals high in (lack of) premeditation, one can imagine that risky sex might serve as an emotion regulation function either to ameliorate distress associated with PTSD-related negative affect, or to promote or prolong experiences of positive affect associated with sexual activity. In both of these scenarios, the short-term benefit of their actions (i.e., reduction in negative emotions or increase/protraction of positive emotions) outweighs the possible negative consequences associated with engaging in risky sex, a feature characteristic of the trait of (lack of) premeditation. Further exploration of the role of (lack of) premeditation, a trait that has not been investigated as frequently as sensation seeking and positive/negative urgency, in the association between PTSD and risky sexual behavior is needed.

\section{Implications}

While our findings offer indirect support for the theory that risky sex may be used as an emotion regulation strategy to diffuse or avoid negative emotions, and/or to elicit/prolong positive emotions among college students with PTSD, future studies are needed to specifically test the nature of how this theory is operating in the context of negative urgency and (lack of) premeditation. Specifically, future studies should assess possible motives for engaging in risky sexual behavior, as well as test whether these behaviors are more likely to occur on days in which negative (or positive) affect are high via daily diary or ecological momentary assessment methodology. 
Counter to hypotheses, sensation seeking, positive urgency, and (lack of) perseverance did not interact with PTSD symptom severity to predict risky sexual behavior. However, in all three models, significant main effects for PTSD symptoms and the respective impulsivity disposition were found, suggesting a potential additive risk model wherein both PTSD symptoms and dispositions of sensation seeking, positive urgency and (lack of) perseverance uniquely predict increased engagement in risky sexual behavior.

\section{Limitations}

There are several limitations to the present study that should be addressed. First, data were cross-sectional, which precludes conclusions regarding temporal or causal relationships among the constructs investigated in this study. Prospective data are needed to determine whether PTSD symptoms and specific impulsive personality traits operate in an additive or interactive way to prospectively predict increased engagement in risky sexual behavior in trauma exposed college students and other populations. Moreover, although the present investigation evaluated a moderating role of impulsive personality traits on the relationship between PTSD symptoms and risky sexual behavior, it is also possible that individuals high in impulsivity (or certain facets of impulsivity) may be more likely to develop symptoms of PTSD, which may in turn lead to increased engagement in risky sexual behaviors. It is also possible that traumatic events, including sexual trauma, or the presence of PTSD symptoms (particularly chronically) may lead to increases in impulsive personality traits over time.

Additional limitations included reliance on self-report, including retrospective self-report of past-year engagement in risky sexual behavior. Use of methods such as 
daily diary tracking may capture a more valid measurement of participants' sexual behavior by reducing potential for recall biases that occurs with questionnaires assessing behavior over long periods. Prior studies have specifically recommended using daily diary over retrospective self-report questionnaires as this method provides a more accurate representation of recent sexual behaviors (Coxon, 1999; Lim et al., 2010; McAuliffe, 2007). Future research should also consider use of an interview measure of PTSD, such as the Clinician-Administered PTSD Scale for DSM-5 (CAPS-5; Weathers, Blake et al., 2013a), as this measure would allow us to determine the diagnostic status of participants and overcome possible reporter biases of the self-report measure. However, prior studies have found comparable diagnostic performance between the PCL-5 and the CAPS-5 (Bovin et al., 2016; Marmar et al., 2015).

The present study also did not examine the impact of alcohol or other substance use, which will be critical for future studies, given that college students engage in high rates of alcohol and illicit drug use (particularly marijuana use); and substance use has been strongly linked to impulsivity, increased engagement in risky sexual behavior, and PTSD symptoms (Arria et al., 2017; Dworkin, Wanklyn, Stasiewicz, \& Coffey, 2018; Jacobsen, Southwick, Kosten, 2001; Park, Scott, Adams, Brindis, \& Irwin, 2014; Smith \& Cyders, 2016; Ritchwood, Ford, DeCoster, Sutton, \& Lochman, 2015). Though inclusion of both male and female participants was a strength of the present study, small numbers of males and individuals with sexual trauma did not allow us to conduct the primary analyses by biological sex and sexual trauma. Future studies are needed with larger numbers of males and greater reports of sexual trauma in both males and females to determine whether these differences remain. 
Due to the low rate of probable PTSD in this sample, our results may not generalize to samples with more severe PTSD symptom presentations. The most commonly reported risky sexual acts in the present sample were unprotected sex with a non-monogamous partner, one-night stands, sex under the influence of alcohol or drugs, and sex with someone not well-known. The findings of this study may not generalize to other groups who engage in risky sexual behaviors that differ from those reported here (e.g., sex in exchange for drugs or money). Lastly, our sample was predominantly Caucasian and future research is needed to determine whether these results generalize to more ethnically and racially diverse samples.

\section{Conclusions}

Despite these limitations, results from the present study advance the currently limited body of research regarding the relationship between PTSD symptoms and risky sexual behavior among college students. This study supports the finding that PTSD symptoms and impulsive personality traits are positively related to risky sexual behavior. In addition, findings suggest that the relationship between PTSD symptoms and risky sexual behavior may be strengthened among individuals high in certain impulsive personality traits (i.e., negative urgency, [lack of] premeditation) that have been linked to risky sexual behavior. Risky sexual behavior is associated with several negative health outcomes, including unplanned pregnancies, sexually transmitted infections, and risk for additional trauma, such as sexual assault; highlighting the need for continued elucidation of the factors and processes involved in predicting risky sexual behavior in college students and other populations. 


\section{References}

American College Health Association. (2012). American College Health AssociationNational College Health Assessment II: Reference Group Data Report Fall 2012. Hanover, MD: American College Health Association.

American Psychiatric Association. (2013). Diagnostic and statistical manual of mental disorders (5th ed.). Washington, DC: American Psychiatric Publishing.

Arria, A. M., Caldeira, K. M., Allen, H. K., Bugbee, B. A., Vincent, K. B., \& O'Grady, K. E. (2017). Prevalence and incidence of drug use among college students: An 8year longitudinal analysis. The American Journal of Drug and Alcohol Abuse, 43(6), 711-718.

Baker, T. B., Piper, M. E., McCarthy, D. E., Majeskie, M. R., \& Fiore, M. C. (2004). Addiction motivation reformulated: an affective processing model of negative reinforcement. Psychological review, 111(1), 33-51.

Banducci, A., Hoffman, E., Lejuez, C., \& Koenen, K. (2014). The impact of childhood abuse on inpatient substance users: Specific links with risky sex, aggression, and emotion dysregulation. Child Abuse \& Neglect, 38, 928-938.

Batten, S. V., Follette, V. M., \& Aban, I. B. (2002). Experiential avoidance and high-risk sexual behavior in survivors of child sexual abuse. Journal of Child Sexual Abuse, 10(2), 101-120.

Birkley, E. L., \& Smith, G. T. (2011). Recent advances in understanding the personality underpinnings of impulsive behavior and their role in risk for addictive behaviors. Current Drug Abuse Reviews, 4(4), 215-227.

Birthrong, A., \& Latzman, R. D. (2014). Aspects of impulsivity are differentially associated with risky sexual behaviors. Personality and Individual Differences, 57, 8-13.

Blayney, J. A., Lewis, M. A., Kaysen, D., \& Read, J. P. (2018). Examining the influence of gender and sexual motivation in college hookups. Journal of American College Health, 1-9.

Blevins, C. A., Weathers, F. W., Davis, M. T., Witte, T. K., \& Domino, J. L. (2015). The Posttraumatic Stress Disorder Checklist for DSM-5 (PCL-5): Development and initial psychometric evaluation. Journal of Traumatic Stress, 28(6), 489-498.

Bogg, T., \& Roberts, B. W. (2004). Conscientiousness and health-related behaviors: a meta-analysis of the leading behavioral contributors to mortality. Psychological Bulletin, 130(6), 887-919. 
Bovin, M. J., Marx, B. P., Weathers, F. W., Gallagher, M. W., Rodriguez, P., Schnurr, P. P., \& Keane, T. M. (2016). Psychometric properties of the PTSD checklist for diagnostic and statistical manual of mental disorders-fifth edition (PCL-5) in veterans. Psychological Assessment, 28(11), 1379.

Brooks-Gunn, J., \& Paikoff, R. (1997). Sexuality and developmental transitions during adolescence. In J. Schulenberg, J. L. Maggs, \& K. Hurrelmann (Eds.), Health risks and developmental transitions during adolescence (pp. 190-219). New York, NY, US: Cambridge University Press.

Buhi, E. R., Marhefka, S. L., \& Hoban, M. T. (2010). The state of the union: Sexual health disparities in a national sample of US college students. Journal of American College Health, 58(4), 337-346.

Byrnes, J., Miller, D., \& Schaffer, W. (1999). Gender differences in risk- taking: A metaanalysis. Psychological Bulletin, 125, 367-383.

Cavanaugh, C. E., Hansen, N. B., \& Sullivan, T. P. (2010). HIV sexual risk behavior among low-income women experiencing intimate partner violence: The role of posttraumatic stress disorder. AIDS and Behavior, 14(2), 318-327.

Centers for Disease Control and Prevention. Sexually Transmitted Disease Surveillance 2017. Atlanta: U.S. Department of Health and Human Services; 2018.

Christiansen, D. M., \& Hansen, M. (2015). Accounting for sex differences in PTSD: A multi-variable mediation model. European Journal of Psychotraumatology, 6(1), $1-10$.

Contractor, A. A., Weiss, N. H., Dranger, P., Ruggero, C., \& Armour, C. (2017). PTSD's risky behavior criterion: Relation with DSM-5 PTSD symptom clusters and psychopathology. Psychiatry Research, 252, 215-222.

Cooper, M. L. (2002). Alcohol use and risky sexual behavior among college students and youth: evaluating the evidence. Journal of Studies on Alcohol, 14, 101-117.

Cox, W. M., \& Klinger, E. (1988). A motivational model of alcohol use. Journal of Abnormal Psychology, 97(2), 168-180.

Coxon, A. P. (1999). Parallel accounts? Discrepancies between self-report (diary) and recall (questionnaire) measures of the same sexual behaviour. AIDS Care, 11(2), 221-234.

Cross, C. P., Cyrenne, D. L. M., \& Brown, G. R. (2013). Sex differences in sensationseeking: a meta-analysis. Scientific reports, 3, 1-5.

Cyders, M. A., \& Smith, G. T. (2008). Emotion-based dispositions to rash action: 
positive and negative urgency. Psychological Bulletin, 134(6), 807-828.

Cyders, M. A., \& Smith, G. T. (2007). Mood-based rash action and its components: Positive and negative urgency. Personality and Individual Differences, 43(4), 839-850.

Dawson, J. F. (2014). Moderation in management research: What, why, when and how. Journal of Business and Psychology, 29, 1-19.

Deckman, T., \& DeWall, C. N. (2011). Negative urgency and risky sexual behaviors: A clarification of the relationship between impulsivity and risky sexual behavior. Personality and Individual Differences, 51(5), 674-678.

Dennison, O., Wu, Q., \& Ickes, M. (2014). Prevalence of human immunodeficiency virus testing and associated risk factors in college students. Journal of American College Health, 62(5), 309-318.

Dworkin, E. R., Wanklyn, S., Stasiewicz, P. R., \& Coffey, S. F. (2018). PTSD symptom presentation among people with alcohol and drug use disorders: comparisons by substance of abuse. Addictive Behaviors, 76, 188-194.

Eisenberg, M. E., Lust, K. A., \& Garcia, C. M. (2014). Differences in sexual behaviors among unmarried sexually active students at 2-and 4-year colleges. Research in Nursing \& Health, 37(2), 128-134.

Epstein, M., Calzo, J. P., Smiler, A. P., \& Ward, L. M. (2009). Anything from making out to having sex: Men's negotiations of hooking up and friends with benefits scripts. Journal of Sex Research, 46(5), 414-424.

Filipas, H. H., \& Ullman, S. E. (2006). Child sexual abuse, coping responses, self-blame, posttraumatic stress disorder, and adult sexual revictimization. Journal of Interpersonal Violence, 21(5), 652-672.

Fromme, K., Corbin, W. R., \& Kruse, M. I. (2008). Behavioral risks during the transition from high school to college. Developmental Psychology, 44(5), 1497-1504.

Garcia, J. R., Reiber, C., Massey, S. G., \& Merriwether, A. M. (2012). Sexual hookup culture: A review. Review of General Psychology, 16(2), 161-176.

Gray, M. J., Litz, B. T., Hsu, J. L., \& Lombardo, T. W. (2004). Psychometric properties of the life events checklist. Assessment, 11(4), 330-341.

Holmes, W., Foa, E., \& Sammel, M. (2005). Men's pathways to risky sexual behavior: Role of co-occurring childhood sexual abuse, posttraumatic stress disorder, and depression histories. Journal of Urban Health, 82(1), i89-i99. 
Horvath, P., \& Zuckerman, M. (1993). Sensation seeking, risk appraisal, and risky behavior. Personality and Individual Differences, 14(1), 41-52.

Hoyle, R. H., Fejfar, M. C., \& Miller, J. D. (2000). Personality and sexual risk taking: A quantitative review. Journal of Personality, 68(6), 1203-1231.

Hutton, H. E., Treisman, G. J., Hunt, W. R., Fishman, M., Kendig, N., Swetz, A., \& Lyketsos, C. G. (2001). HIV risk behaviors and their relationship to posttraumatic stress disorder among women prisoners. Psychiatric Services, 52(4), 508-513.

Jacobsen, L. K., Southwick, S. M., \& Kosten, T. R. (2001). Substance use disorders in patients with posttraumatic stress disorder: A review of the literature. American Journal of Psychiatry, 158, 1184-1190.

Johnson, E. H., Jackson, L. A., Hinkle, Y., Gilbert, D., Hoopwood, T., Lollis, C. M., ... \& Gant, L. (1994). What is the significance of black-white differences in risky sexual behavior? Journal of the National Medical Association, 86(10), 745-759.

Lim, M., Sacks-Davis, R., Aitken, C., Hocking, J., \& Hellard, M. (2010). Randomised controlled trial of paper, online and SMS diaries for collecting sexual behaviour information from young people. Journal of Epidemiology and Community Health, 64(10), 885-889.

Lynam, D. R., Smith, G. T., Whiteside, S. P., \& Cyders, M. A. (2006). The UPPS-P: Assessing five personality pathways to impulsive behavior. West Lafayette, IN: Purdue University.

Marmar, C. R., Schlenger, W., Henn-Haase, C., Qian, M., Purchia, E., Li, M..... \& Karstoft, K. I. (2015). Course of posttraumatic stress disorder 40 years after the Vietnam War: findings from the National Vietnam Veterans Longitudinal Study. JAMA Psychiatry, 72(9), 875-881.

McAuliffe, T. L., DiFranceisco, W., \& Reed, B. R. (2007). Effects of question format and collection mode on the accuracy of retrospective surveys of health risk behavior: a comparison with daily sexual activity diaries. Health Psychology, 26(1), 60-67.

Messman-Moore, T., Walsh, K., \& DiLillo, D. (2010). Emotion dysregulation and risky sexual behavior in revictimization. Child Abuse \& Neglect, 34, 967-976.

Messman-Moore, T. L., Ward, R. M., \& Brown, A. L. (2009). Substance use and PTSD symptoms impact the likelihood of rape and revictimization in college women. Journal of Interpersonal Violence, 24(3), 499-521.

Miller, J., Flory, K., Lynam, D., \& Leukefeld, C. (2003). A test of the four-factor model of impulsivity-related traits. Personality and Individual Differences, 34, 14031418 . 
Moore, A. A., Overstreet, C., Kendler, K. S., Dick, D. M., Adkins, A., \& Amstadter, A. B. (2017). Potentially traumatic events, personality, and risky sexual behavior in undergraduate college students. Psychological Trauma: Theory, Research, Practice, and Policy, 9(1), 105-112.

Munroe, C. D., Kibler, J. L., Ma, M., Dollar, K. M., \& Coleman, M. (2010). The relationship between posttraumatic stress symptoms and sexual risk: Examining potential mechanisms. Psychological Trauma: Theory, Research, Practice, and Policy, 2(1), 49-53.

Newman, P. A., \& Zimmerman, M. A. (2000). Among urban African American youth: a multivariate approach. AIDS Education and Prevention, 12(4), 308-325.

Nock, M. K., \& Prinstein, M. J. (2004). A functional approach to the assessment of selfmutilative behavior. Journal of Consulting and Clinical Psychology, 72(5), 885890.

Olff, M. (2017). Sex and gender differences in post-traumatic stress disorder: an update. European Journal of Psychotraumatology, 8(sup4), 1351204.

Oswalt, S. B., \& Wyatt, T. J. (2014). But I'm married: understanding relationship status and college students' sexual behaviors. American Journal of Sexuality Education, 9(1), 4-20.

Owen, J. J., Rhoades, G. K., Stanley, S. M., \& Fincham, F. D. (2010). "Hooking up" among college students: Demographic and psychosocial correlates. Archives of Sexual Behavior, 39(3), 653-663.

Park, M. J., Scott, J. T., Adams, S. H., Brindis, C. D., \& Irwin Jr, C. E. (2014). Adolescent and young adult health in the United States in the past decade: Little improvement and young adults remain worse off than adolescents. Journal of Adolescent Health, 55(1), 3-16.

Paul, E. L., \& Hayes, K. A. (2002). The causalities of "causal sex": A qualitative exploration of the phenomenology of college students' hookups. Journal of Social and Personal Relationships, 19, 639-661.

Reisner, S., Mimiaga, M., Safren, S., \& Mayer, K. (2009). Stressful or traumatic life events, post-traumatic stress disorder (PTSD) symptoms, and HIV sexual risk taking among men who have sex with men. AIDS Care, 21, 1481-1489.

Ritchwood, T. D., Ford, H., DeCoster, J., Sutton, M., \& Lochman, J. E. (2015). Risky sexual behavior and substance use among adolescents: A meta-analysis. Children and Youth Services Review, 52, 74-88. 
Shulman, E. P., Harden, K. P., Chein, J. M., \& Steinberg, L. (2015). Sex differences in the developmental trajectories of impulse control and sensation-seeking from early adolescence to early adulthood. Journal of Youth and Adolescence, 44(1), 117.

Simons, J. S., Maisto, S. A., \& Wray, T. B. (2010). Sexual risk taking among young adult dual alcohol and marijuana users. Addictive Behaviors, 35(5), 533-536.

Smith, D. W., Davis, J. L., \& Fricker-Elhai, A. E. (2004). How does trauma beget trauma? Cognitions about risk in women with abuse histories. Child Maltreatment, 9(3), 292-303.

Smith, G. T., \& Cyders, M. A. (2016). Integrating affect and impulsivity: The role of positive and negative urgency in substance use risk. Drug and Alcohol Dependence, 163, S3-S12.

Smith, G. T., Fischer, S., Cyders, M. A., Annus, A. M., Spillane, N. S., \& McCarthy, D. M. (2007). On the validity and utility of discriminating among impulsivity-like traits. Assessment, 14(2), 155-170.

Solomon, Z., Ginzburg, K., Neria, Y., \& Ohry, A. (1995). Coping with war captivity: The role of sensation seeking. European Journal of Personality, 9(1), 57-70.

Stinson, R. D. (2010). Hooking up in young adulthood: A review of factors influencing the sexual behavior of college students. Journal of College Student Psychotherapy, 24(2), 98-115.

Tolin, D. F., \& Foa, E. B. (2008). Sex differences in trauma and posttraumatic stress disorder: A quantitative review of 25 years of research. Psychological Bulletin, 132(6), 959-992.

Walsh, K., Latzman, N., \& Latzman, R. (2014). Pathway from child sexual and physical abuse to risky sex among emerging adults: The role of trauma-related intrusions and alcohol problems. Journal of Adolescent Health, 54, 442-448.

Weathers, F.W., Blake, D.D., Schnurr, P.P., Kaloupek, D.G., Marx, B.P., \& Keane, T.M. (2013). The Clinician-Administered PTSD Scale for DSM-5 (CAPS-5). Interview available from the National Center for PTSD at www.ptsd.va.gov.

Weathers, F. W., Blake, D. D., Schnurr, P. P., Kaloupek, D. G., Marx, B. P., \& Keane, T. M. (2013). The life events checklist for DSM-5 (LEC-5). Instrument available from the National Center for PTSD. Boston (MA): National Center for PTSD.

Weathers, F. W., Litz, B. T., Keane, T. M., Palmieri, P. A., Marx, B. P., \& Schnurr, P. P. (2013). The PTSD Checklist for DSM-5 (PCL-5). Scale available from the National Center for PTSD. Boston (MA): National Center for PTSD. 
Weiss, N. H., Tull, M. T., Davis, L. T., Searcy, J., Williams, I., \& Gratz, K. L. (2015). A preliminary experimental investigation of emotion dysregulation and impulsivity in risky behaviours. Behaviour Change, 32(2), 127-142.

Weiss, N. H., Tull, M. T., Dixon-Gordon, K., \& Gratz, K. L. (2018). Assessing the negative and positive emotion-dependent nature of risky behaviors among substance dependent patients. Assessment, 25(6), 702-715.

Weiss, N. H., Tull, M. T., Sullivan, T. P., Dixon-Gordon, K. L., \& Gratz, K. L. (2015). Posttraumatic stress disorder symptoms and risky behaviors among traumaexposed inpatients with substance dependence: The influence of negative and positive urgency. Drug and Alcohol Dependence, 155, 147-153.

Weiss, N. H., Tull, M. T., Viana, A. G., Anestis, M. D., \& Gratz, K. L. (2012). Impulsive behaviors as an emotion regulation strategy: Examining associations between PTSD, emotion dysregulation, and impulsive behaviors among substance dependent inpatients. Journal of Anxiety Disorders, 26(3), 453-458.

Whiteside, S. P., \& Lynam, D. R. (2001). The five factor model and impulsivity: Using a structural model of personality to understand impulsivity. Personality and Individual Differences, 30(4), 669-689.

Whiteside, S. P., Lynam, D. R., Miller, J. D., \& Reynolds, S. K. (2005). Validation of the UPPS impulsive behaviour scale: a four-factor model of impulsivity. European Journal of Personality: Published for the European Association of Personality Psychology, 19(7), 559-574.

Zapolski, T. B., Cyders, M. A., \& Smith, G. T. (2009). Positive urgency predicts illegal drug use and risky sexual behavior. Psychology of Addictive Behaviors, 23(2), 348-354.

Zuckerman, M. (1994). Behavioral expressions and biosocial bases of sensation seeking. Cambridge University Press. 


\section{Jessica Flores, B.A.}

\section{EDUCATION}

\section{DePaul University}

Chicago, IL

Bachelor of Arts, Psychology

June 2013

\section{SCHOLASTIC AND PROFESSIONAL HONORS}

2016 - Present Lyman T. Johnson Diversity Fellowship, University of Kentucky

Funded \$7,500 for Fall and Spring Semesters by University of Kentucky

2018 Student Professional Diversity Development Award

Funded $\$ 300$ by University of Kentucky’s Center for Graduate and Professional Diversity Initiatives

2017 Multicultural Student Professional Development Award

Funded $\$ 350$ by The Kentucky Psychological Association

2017 New Horizons Scholarship, University of Kentucky (Awarded \$500)

2013 Honors Psychology, DePaul University

2013 Undergraduate Research Assistant Program Grant, DePaul University Funded \$1,350 for Winter and Spring Quarters by Department of Psychology

2009 - 2013 Dean's List College of Science and Health, DePaul University

2009 - 2013 Ronald E. McNair Postbaccalaureate Achievement Program, DePaul University

2009 - 2013 Recipient, Mazza Foundation Scholarship (Awarded \$10,000 Annually)

Summer 2012 McNair Summer Research Opportunities Program, DePaul University Funded $\$ 2,000$ by McNair Scholars Program

2012 Undergraduate Research Assistant Program Grant, DePaul University Funded \$1,350 for Summer and Autumn Quarters by Department of Psychology

2012 Recipient, Center for Intercultural Programs Scholarship (Awarded \$3,394)

Summer 2011 Latino Mental Health Program, Minority Health International Research Training, University of Southern California and Benemérita Universidad Autónoma de Puebla 
Funded $\$ 7,790$ by National Center on Minority Health and Health Disparities

2010 - 2011 Doctoral-Undergraduate Opportunities for Research Scholarship, DePaul University

Funded \$750 for Autumn to Spring Quarters by Department of Psychology

Summer 2010 Summer Research Opportunities Program, University of Illinois at Chicago Funded $\$ 3,600$ by Committee on Institutional Cooperation

2009 - 2010 Center for Access and Attainment Research Training, DePaul University Funded $\$ 2,500$ by Center for Access and Attainment

2008 - 2010 Americorps Midwest Campus Compact Citizen-Scholar

Educational Fellowship, Fellow and Mentor (awarded \$3,000 stipend, \$1,000 grant annually)

\section{RESEARCH EXPERIENCE}

August 2016 - Present

June 2013 - July 2016

March 2010 - June 2013

October 2010 - June 2013

October 2010 - June 2013
Graduate Research Assistant, Department of Psychology

University of Kentucky, Lexington, KY

Stress, Trauma, and Recovery Research Center

Supervisor: Christal Badour, PhD

Project Coordinator, Department of Psychological Science Case Western Reserve University, Cleveland, $\mathrm{OH}$

PTSD Treatment and Research Program

Supervisor: Norah Feeny, $\mathrm{PhD}$

Project: Optimizing Treatment for PTSD (OPT): PE vs. PE plus

Sertraline (R01 MH066348)

Undergraduate Research Assistant, Department of Psychology DePaul University, Chicago, IL

Chicago Healthy Teens, Families, and Schools Laboratory

Supervisor: Jocelyn Smith Carter, PhD

Undergraduate Research Assistant, Department of Psychology DePaul University, Chicago, IL

Stress and Coping Project

Supervisor: Kathryn Grant, $\mathrm{PhD}$

Undergraduate Research Assistant, Department of Psychology DePaul University, Chicago, IL

Latino Oxford House Research Laboratory

Director: Leonard Jason, PhD

Project Supervisor: Julia DiGangi, PhD 
Summer 2011

Summer 2010

Dec. 2009 - October 2010
Undergraduate Research Fellow, Minority Health International Research Training Funded by the National Center on Minority Health and Health Disparities University of Southern California, Los Angeles, CA Benemérita Universidad Autónoma de Puebla, Puebla, MX Latino Mental Health Program

Supervisors: Steven Lopez, PhD, and Maria del Carmen LaraMuñoz, M.D

Undergraduate Research Fellow, Summer Research Opportunities Program Funded by the Committee on Institutional Cooperation University of Illinois at Chicago, Chicago, IL Wiley Eyetracking and Cognition Laboratory Supervisors: Jennifer Wiley, PhD, and Patrick Cushen, MA

Undergraduate Research Assistant, Department of Psychology

DePaul University, Chicago, IL

First-Year Students' Adjustment to College Project Supervisor: Luciano Berardi, PhD

\section{PEER-REVIEWED MANUSCRIPTS}

Hood, C. O., Jones, A. C., Flores, J., Badour, C. L., \& Feldner, M. T. (Under Review). Distress tolerance interacts with trauma-related anger, sadness, and shame to predict posttraumatic stress symptoms following sexual victimization.

Sonnier, H., Brake, C. A., Flores, J., \& Badour, C. L. (2019). Posttraumatic stress and hazardous alcohol use in trauma-exposed young adults: Indirect effects of selfdisgust. Substance Use \& Misuse, 54, 1051-1059.

\section{POSTER and ORAL PRESENTATIONS}

Badour, C. L., Flores, J., Hood, C. O., \& Brake, C. A. (November, 2019). Medical and nonmedical prescription opioid use patterns in individuals with PTSD: Does day-to-day variability in PTSD symptom severity predict co-use of prescription opioids and other substances? In Badour, C. L. (chair) and Back, S. E.(discussant). Seeking clarity in the face of an epidemic: Dissecting associations among trauma, PTSD and opioid use. Symposium submitted for presentation at the $35^{\text {th }}$ annual meeting of the International Society for Traumatic Stress Studies, Boston, MA.

Badour, C. L., Jones, A. C., Flores, J., \& Hood, C. O. (November, 2019). Traumarelated shame as a prospective predictor of non-medical prescription opioid use and motives for use among adults with PTSD. In McDevitt-Murphy, M. (chair). Negative emotion in PTSD: Correlates and Consequences. Symposium submitted for presentation at the $35^{\text {th }}$ annual meeting of the International Society for Traumatic Stress Studies, Boston, MA. 
Flores, J., Brake, C. A., Grieff, A. M, Gibson, A. R., \& Badour, C. L., (2019, March). The mediating role of emotion dysregulation in the relation between PTSD symptoms and affect-driven risky sexual behavior. Poster presented at the $39^{\text {th }}$ annual meeting of Anxiety and Depression Association of America, Chicago, IL.

Cox, K. S., Badour, C. L., Flores, J., Goodnight, J. R. M., Tuerk, P. W., \& Rauch, S. A. (2019, March). Sexual health among veterans seeking outpatient treatment for PTSD: Does successful PTSD treatment also yield improvements in sexual desire? Poster presented at the $39^{\text {th }}$ annual meeting of the Anxiety and Depression Association of America, Chicago, IL.

Hood, C. O., Flores, J., \& Badour, C. L. (March, 2019) Proximal associations between pain, PTSD, and non-medical prescription opioid use: Results from a daily diary study. Presented at the Substance Use Research Day, University of Kentucky, Lexington, KY.

Flores, J., Brake, C. A., Grieff, A. M., \& Badour, C. L. (2018, November). The relationship between posttraumatic stress symptoms and help-seeking treatment attitudes: The role of self-disgust. Poster presented at the 34th annual meeting of the International Society of Traumatic Stress Studies, Washington, D.C.

Hood, C. O., Bowen, M. E., Blevins, T. R., Jones, A. C., Flores, J., \& Badour, C. L. (2018, November). Distress tolerance moderates the relation between posttraumatic stress symptoms and cannabis use among women with interpersonal trauma histories. Poster presented at the 34th annual meeting of the International Society of Traumatic Stress Studies, Washington, D.C.

Flores, J., Jones, A. C., \& Badour, C. L. (2018, January). Challenges in recruiting participants from studies on trauma: Lessons learned from samples with interpersonal trauma, PTSD, and substance abuse. Invited presentation for the University of Kentucky Center for Clinical and Translational Science (CCTS) Participant Recruitment Services Workshop.

Flores, J., Brake C. A., Hood, C. O., Ray, M., Watts, G., \& Badour, C. L. (2017, March). Facets of impulsivity moderate the association between posttraumatic stress and risky sexual behavior. Poster presented at the $38^{\text {th }}$ annual meeting of the Anxiety and Depression Association of America, Washington, D.C.

Flores, J., Badour, C. L., Brake, C. A., Hood, C. O., \& Ellis, H. B. (2017, November). Selfdisgust as a potential mechanism in the association between posttraumatic stress symptoms and risky sexual behavior. Poster presented at the $33^{\text {rd }}$ annual meeting of the International Society of Traumatic Stress Studies, Chicago, IL. 
Hood, C. O., Badour, C. L., Jones, A. C., Flores, J., \& Feldner, M. T. (2017, November). Distress tolerance moderates the relationship between peritraumatic emotion and symptoms of posttraumatic stress among women with a history of sexual trauma. Poster presented at the $33^{\text {rd }}$ annual meeting of the International Society of Traumatic Stress Studies, Chicago, IL.

Flores, J., Badour, C. L., Brake, C. A., Hood, C. O., \& Feldner, M. T. (2016, April). Disgust propensity and sensitivity as moderators of the relation between PTSD symptoms and sexual pain among trauma-exposed women. Poster presented at the $37^{\text {th }}$ annual meeting of the Anxiety and Depression Association of America, San Francisco, CA.

Flores, J., Hood, C., Badour, C. L., Gros, D. F., Szafranski, D. D., \& Acierno, R. (2016, November). Sexual problems predict PTSD and depression symptom change among male OEF/OIF veterans completing exposure therapy. Poster presented at the $50^{\text {th }}$ annual meeting of the Association for Behavioral and Cognitive Therapies, Trauma and PTSD Special Interest Group, New York, NY.

Cooper, A.A., Flores, J., Feeny, N.C., \& Zoellner, L.A. (2015, November). The impact of baseline anger on PTSD symptom change after initial imaginal exposure in prolonged exposure for PTSD. Poster presented at the $49^{\text {th }}$ annual meeting of the Association for Behavioral and Cognitive Therapies Convention, Chicago, IL.

Flores, J., Radjenovic, X., Cooper, A.A., Feeny, N.C., \& Zoellner, L.A. (2015, April). Does anger predict early therapeutic alliance or attrition in treatment for posttraumatic stress disorder (PTSD)? Poster presented at the $35^{\text {th }}$ annual meeting of the Anxiety and Depression Association of America, Miami, FL.

Lewis, J., Arizaga, J., Farrell, S., Flores, J., Floyd, A., \& Grant, K. E. (2013, November). Delineating African American youth depression rates in a nationally representative sample: Combine effects of race and socioeconomic status. Poster presented the $47^{\text {th }}$ annual meeting of the Association for Behavioral and Cognitive Therapies Convention, Nashville, TN.

Flores, J., \& Bottom, T. (2013, May). A new psychology of men: A case study. Poster presented at DePaul University's $18^{\text {th }}$ Annual Psychology Night Conference, Chicago, IL.

Flores, J., DiGangi, J., \& Jason, L. (2013, May). Disclosure and social acknowledgment in Latinos living in Oxford Homes. Poster presented at DePaul University's $18^{\text {th }}$ Annual Psychology Night Conference, Chicago, IL.

Carothers, K. J., Rabideau, R. L., Sozzer, F. H., Dulaney, E. S., Flores, J., \& Grant, K. E. (2012, November). Towards the development of a culturally and contextually relevant model of coping for low-income, urban African American youth. Poster presented at $46^{\text {th }}$ annual meeting of the Association for Behavioral and Cognitive Therapies Convention, National Harbor, MD. 
Labarrie, T. L., Huttmann, G., Marshall, H., Flores, J., Grant, K. E., \& Amrhein, K. (2012, August). Reports of racial discrimination by a diverse sample of low-income, urban youth. Poster presented at the $120^{\text {th }}$ annual meeting of the American Psychological Association, Orlando, FL.

Flores, J., \& Lara-Muñoz, C. (2011, August). Suicide risk among medical students at a university in Mexico. Oral presentation presented at the Latino Mental Health Program Symposium, Mexico City, Mexico and poster presented at DePaul University’s McNair Scholars Summer Research Poster Conference, Chicago, IL.

Flores, J., Bostick, S., \& Smith Carter, J. (2011, May). Obesity among ethnic minorities: Demographic, academic and socioemotional correlates. Poster presented at DePaul University's $16^{\text {th }}$ Annual Psychology Night Conference, Chicago, IL and DePaul University's $5^{\text {th }}$ Annual Liberal Arts and Sciences Undergraduate Research Conference, Chicago, IL.

Flores, J., Berardi, L., \& Winczewski, L. (2010, October). First year students' attachment to parents and university. Poster presented at the Midwest EcologicalCommunity Psychology 2010 Conference, Urbana, IL and DePaul University's McNair Scholars Summer Research Poster Conference, Chicago, IL.

Flores, J., Cushen, P., \& Wiley, J. (2010, July). Bilingualism, executive control, and insight problem solving. Poster and roundtable discussion presented at the Committee on Institutional Cooperation (CIC) Summer Research Opportunities Program Research Poster Symposium at The Ohio State University, Columbus, OH and oral presentation presented at the University of Illinois at Chicago Summer Research Opportunities Program Symposium, Chicago, IL.

Jessica Flores 